\title{
Exergetic Assessment in Dairy Industry
}

\author{
Seda Genc \\ Additional information is available at the end of the chapter \\ http://dx.doi.org/10.5772/intechopen.75028
}

\begin{abstract}
Food industry is one of the most energy-consuming industries. Exergy analysis for several food production lines had been the subject of some studies in the past. However, dairy industry has a significant importance among food industry from energetic point of view since it covers many heating and cooling processes. Energy and exergy analyses are commonly used techniques for performance assessment of thermal system where exergy analysis is known as the powerful tool. In this context, exergy calculation methodology and a review of exergetic assessment in dairy industry are the subject of this study for the first time to the best of author's knowledge. In this chapter, first of all, exergy analysis methodology is presented, and next, assessment of exergy analysis of some dairy processes including milk pasteurization, milk powder process, flavored yoghurt production, yoghurt production and yoghurt drink processes are reviewed, comprehensively. Application of the exergy analysis in dairy industry supplies possibility to perform exergetic design, simulation, analysis and performance assessment.
\end{abstract}

Keywords: exergy, food, dairy products, milk processing, liquid milk, milk powder, yoghurt, yoghurt drink

\section{Introduction}

Milk is one of the most consumed foodstuff with its perfect nutritional qualities. It is a good source of not only carbohydrate, protein and fat but also vitamins (A, B2, B12, D) and minerals (calcium, potassium, phosphorous, iodine) [1]. The constituents of milk provide to have stronger bones, support immunity and give energy to the body. However, after milking, milk is processed immediately into several dairy products namely yoghurt, cheese, butter, and so on because of its easily spoiled characteristics [2]. 
Total milk production is $704 \mathrm{M}$ tones/year, globally and the top three producer countries are the USA, India and China [3]. The World dairy industry market value is USD 336 billion in 2014; however, due to its very dynamic pattern, its market value displays continually growing trends which are forecasted to increase 32\% generating USD 442 billion value in 2019. According to FAO, consumption of dairy products is consequently expected to increase by $20 \%$ or more before 2021 . In this context, dairy production and dairy processing clearly appear as industries of significant importance for next decades $[4,5]$.

Dairy plants with different capacities and products are located all over the world. In general, it can be classified into different subsectors based on dairy products such as liquid milk, butter, yoghurt, cheese, milk powder, and so on. All the production lines at dairy industry include a number of unit operations namely cooling, thermisation, separation, homogenization, heat treatment, evaporation, drying, and so on. The major dairy products and their processing lines are schematized in Figure 1. After milking, physical, chemical, biochemical and microbial changes occur in the milk. The first process applied to the milk is cooling to prevent most of changes mentioned above. In some cases, milk is immediately cooled at the farm and transported to the factory with cold chain and continue to be stored in cooled tank in the factory. For some dairy plants with high capacity, the pasteurization or processing following raw milk reception is not possible. Then, milk is stored in cooling tanks to prevent deterioration, but if storage time will be long, pre-heat treatment known as thermisation is applied to the milk. The aim of thermisation is to inhibit microbial growth before pasteurization process and is applied at $63-65^{\circ} \mathrm{C}$ for $15 \mathrm{~s}$ operating conditions which is below pasteurization temperature [1].

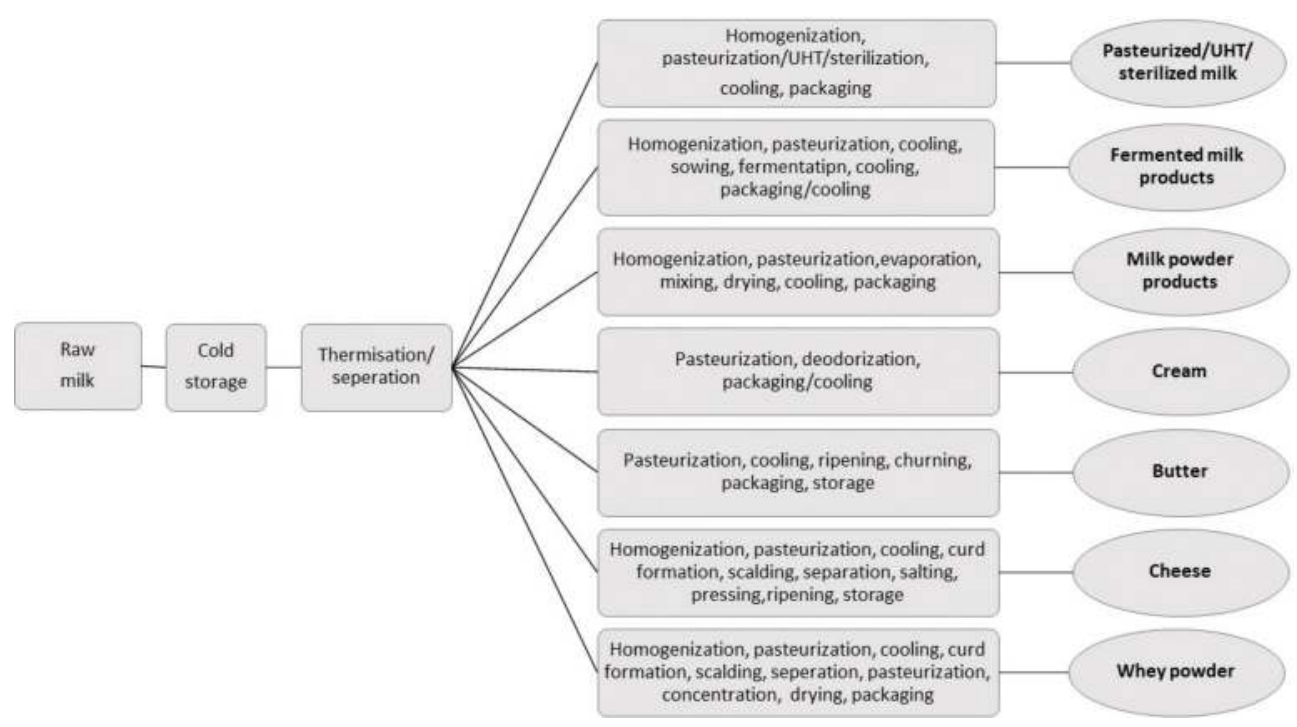

Figure 1. The major dairy products and unit operations take place their processing line [3]. 
In many dairy processes, it is necessary to separate cream from milk to be able to standardize the milk. In this context, milk is fed to the centrifuge to obtain cream and skim milk, individually. Then, cream is processed into cream and butter production and skim milk goes through other production lines. Depending on product type, fat content of milk is standardized by mixing skim milk and fat for other production processes. Homogenization is commonly used operation in dairy industry. It is carried out to disrupt fat globules of milk into smaller ones. Homogenizers are a kind of high pressure pump which forces milk through a close-fitting hole. This process is mostly used for long-life liquid milk production, fermented milk products, milk powder and condensed milk production.

Heat treatment (pasteurization and sterilization) is the most important and used process in dairy industry to kill unwanted microorganisms causing spoilage. During heat treatment, several changes occur depending on length and temperature of heating. For example, pasteurization can be applied low or high temperatures in which the former inhibits most of the microorganisms and some enzymes' activity with a condition of almost $74^{\circ} \mathrm{C}, 15 \mathrm{~s}$. On the other hand, the latter is generally carried out at higher temperatures (e.g., $90^{\circ} \mathrm{C}, 15 \mathrm{~s}$ ) by killing all vegetative microorganisms and inactivating most enzymes. The other heat treatment, sterilization (e.g., $20 \mathrm{~min}$ at $118^{\circ} \mathrm{C}$ ), kills all microorganisms including spores leading to some undesirable changes in the milk. To be able to minimize these changes, ultrahigh temperature heating (UHT) was developed to sterilize milk at higher temperature and lower time compared to sterilization (e.g., at $145^{\circ} \mathrm{C}$ for a few seconds). Evaporation is another unit operation applied to remove water from milk to obtain more concentrated product. The other process called as drying is used to manufacture dairy product in powder form [1,2].

Nowadays, energy shortage and carbon emission increase in the atmosphere are two major problems facing human kind. For that reason, the need to control and improve energyconsuming process and decrease emissions is paramount. As explained above, the production of dairy products needs significant amount of energy since most of the production lines have heating and cooling applications beside electricity. Recently, there is an increase attention to utilize energy in more efficient way and decrease energy consumption because energy costs are increasing depending on fossil fuel shortage and rise in energy prices affects mainly energy-consuming sectors including dairy industry. Despite the fact that energy sector is in the search of renewable energy sources, dependence on fossil fuels is of still concern.

A thermodynamical analysis is performed according to the first and second law of thermodynamics. The first law deals with conservation of energy which means that the input of energy equals the output of energy at steady-state condition, and energy can be converted from one form to another or transferred due to mass, heat and work transport [6, 7]. It should be noted that different types of energies (e.g., heat, work) have different work capacity or quality. For example, if the quality of energy is high, its work capacity would be high. However, the first law does not take into account quality of energy, and it says nothing about how to decrease energy consumption in the system of interest. In other respects, the second law of thermodynamics concerns about quality of energy and exergy or availability term appears which can simply be defined as available energy. 
In reality, all processes are irreversible and result in entropy production due to friction, diffusion, etc. and the second law of thermodynamics states whenever energy is transferred due to heat, internal irreversibilities occur. Since irreversibilities lead to exergy destruction or exergy loss in the system, it is not possible to have $100 \%$ efficiency from a system [8]. The exergy analysis or second law analysis is performed to indicate irreversibilities in the system where the improvements can be made to decrease exergy losses [9-12]. It should be noted that availability or maximum useful work terms represent uppermost level of the work that can be obtained from a system without violating the laws of thermodynamics.

The value of actual work and maximum useful work are not equal to each other except ideal cases. Then, all efforts are to improve the system conditions and catch the minimum difference between availability and actual work value. It is important to realize that the availability of a system in a definite state is strictly attached to the reference conditions (surrounding) as well as properties of the system. In the analysis of availability, firstly initial state is determined and then the work obtained from the system has to be maximized as much as possible in a given context. The entire system has to be in the reference environment at the end of the process. When a system is in equilibrium with its surrounding, it has zero useful work (availability). The thermodynamic equilibrium is classified into three groups: thermal, chemical and mechanical equilibrium $[7,8]$. Therefore, availability is an extensive property depending on the system and environment conditions.

In the literature, exergy analysis was conducted on different systems from machine system to fuel cells and biological systems by various authors. For example, Esen et al. [13] investigated energy and exergy analysis of a ground-coupled heat pump system. They showed that increase in heat source (ground) temperature leads to increase in energetic and exergetic efficiencies of the system. In another study, they studied performance assessment of a ground heat pump system beside technoeconomic analysis [14]. Taner and Sivrioglu [15] performed exery and thermoeconomic analysis of sugar factory having power turbine plant to improve energy economy of the production line, and their results showed that the effect of mass and energy on economic cost was found significant, and it is possible to increase total energy yield depending on design parameters and scenarios. They also studied a model sugar factory to obtain the best energy and exergy efficiency of the system [16]. Taner [17] assessed energetic and exergetic performance of PEM fuel cell to improve efficiency. Taner [18] also optimized drying plant energy and exergy efficiencies by changing mass and energy balance. On the other hand, exergy analysis was conducted on some biological systems on the cellular level $[19,20]$ to determine exergetic efficiency of metabolic pathway. In case of food industry, Genc and Hepbasli studied exergy analysis of potato crisp processes, and they found that the increase in mass flow rate of potato resulted in a rise in the fryer's exergy destruction rate [21]. Genc studied industrial grape molasses production to determine energy need to produce $1 \mathrm{~kg}$ of grape molasses [22]. Genc et al. [23] applied exergy analysis to red wine processing line to assess system's performance. For dairy industry, Yildirim and Genc [24] performed thermodynamic analysis of a milk pasteurization process assisted by geothermal energy and they conducted on energy and exergy analysis of the milk powder production line [25]. Furthermore, they optimized operating conditions of the system in order to increase exergy efficiency [26]. Jokandan et al. [27] applied 
comprehensive exergy analysis of an industrial-scale yoghurt production plant. Erbay et al. [28] studied to optimize operating condition of white cheese powder production. Munir et al. [29] evaluated a milk powder plant as a case study located in New Zealand by applying energy and exergy analyses where the drier has the lowest value and the milk silo has the highest value. Sorgüven and Ozilgen [30] computed energy loss, carbon dioxide emission and exergy loss during flavored yoghurt production. Soufiyan et al. [31] performed exergy analysis of long-life milk production process based on the real factory data and yoghurt drink production line was assessed exergetically by Soufiyan and Aghbashlo [32].

Exergy is one of the keystones of performance assessment. As seen from abovementioned studies, it can be applied to all processes varying from industrial systems to living organisms. Exergy analysis provides to quantify exergy losses by indicating irreversibilities throughout the processes and systems. Nevertheless, it is necessary to express some basic concepts of thermodynamics before introducing the methodology of exergy analysis on food processes. To the best of author's knowledge, a detailed survey of energy and exergy analysis of dairy processes performed up to date have never been studied before in the open literature. Therefore, the aim of this study is to explain the basic of energy and exergy analysis methodology in food processes and to review some important studies on exergy analysis of dairy industry including milk pasteurization, milk powder process, flavored yoghurt production, yoghurt production and yoghurt drink process, comprehensively for the first time.

\section{Methodology}

\subsection{Fundamentals of exergy}

Exergy is known as the work potential or as a measure of available energy. Szargut et al. [8] explained exergy as follows: Exergy is the amount of work obtainable when some matter brought to a state of thermodynamic equilibrium with the common components of the natural surroundings by means of reversible processes. In contrast to energy, exergy is destroyed in all real world processes as entropy is produced. Exergy is not destroyed only in reversible processes. However, in reality, all the processes are irreversible, and exergy is lost during the process.

\subsection{Reference environment (dead state)}

The ability of work for a system is assessed according to a base state. This base state is called as reference, environment or dead state [8]. For example, if the system and the reference environment (reference state or dead state) are in equilibrium, no spontaneous change can occur in the system, and as a result, work cannot be produced. The characterization of reference environment depends on the equilibrium type. If the reference environment and the system are in thermomechanical equilibrium, reference state is characterized by temperature, pressure, height and velocity. If the system under consideration is in chemical equilibrium with reference environment, the reference environment is defined by temperature, pressure and chemical composition. Szargut et al. [8] offered reference environment with three types which are 
gaseous and solid reference found in the atmosphere and reference species dissolved in seawater. The exergy values of these reference substances are assumed as zero. The standard chemical exergies of pure reference species are listed in Szargut et al. [8].

\subsection{Calculation of exergy of food}

Food commodities are mainly composed of water, protein, fat, carbohydrate, fiber and ash, and their thermal properties are crucial to apply thermodynamic analysis of unit operations such as cooling, heating, freezing, drying, and so on. In this part, calculation of exergy of food produces will be explained step by step.

\subsubsection{Specific heat of foods}

Specific heat is a function of temperature and in the study of Choi and Okos [12], the model for specific heat determination of food components was presented as shown in Table 1.

The specific heat of food shows a large difference above and below freezing point. The specific heat is relatively constant with respect to temperature above its freezing point. On the other hand, it has a large decline below the freezing temperature [33].

Generally, the specific heat of a food above the freezing point is the sum of mass average of the specific heat capacities of the food components.

$$
c_{p, \text { food }}=\sum_{i=1}^{n} c_{p, i} w_{i}
$$

where $c_{p, i}$ and $w_{i}$ are the specific heat capacity and mass fraction of the individual food components, respectively. If the food component has a complex structure and all of its ingredients are not known, the formula developed by Chen [33] is used to compute the specific heat of unfrozen food produce

\begin{tabular}{ll}
\hline Component & Specific heat equation $\left(\mathbf{c}_{\mathbf{p}}, \mathbf{J} / \mathbf{( k g . K )}, \mathbf{T}{ }^{\circ} \mathbf{C}\right)$ \\
\hline Protein & $c_{p, \text { protein }}=2.0082 \times 10^{3}+1.2089 \mathrm{~T}-1.3129 \times 10^{-3} T^{2}$ \\
Fat & $c_{p, \text { fat }}=1.9842 \times 10^{3}+1.4733 \mathrm{~T}-4.8008 \times 10^{-3} \mathrm{~T}^{2}$ \\
Carbohydrate & $c_{p, \text { carbohydrate }}=1.5488 \times 10^{3}+1.9625 \mathrm{~T}-5.9399 \times 10^{-3} \mathrm{~T}^{2}$ \\
Fiber & $c_{p, \text { fiber }}=1.8459 \times 10^{3}+1.8306 \mathrm{~T}-4.6509 \times 10^{-3} \mathrm{~T}^{2}$ \\
Ash & $c_{p, \text { ash }}=1.0926 \times 10^{3}+1.8896 \mathrm{~T}-3.6817 \times 10^{-3} \mathrm{~T}^{2}$ \\
Water $\left(-40^{\circ} \mathrm{C} \leq \mathrm{T} \leq 0^{\circ} \mathrm{C}\right)$ & $c_{p, \text { water }}=4.0817 \times 10^{3}-5.3062 \mathrm{~T}+9.9516 \times 10^{-1} T^{2}$ \\
Water $\left(0^{\circ} \mathrm{C} \leq \mathrm{T} \leq 150^{\circ} \mathrm{C}\right)$ & $c_{p, \text { water }}=4.1762 \times 10^{3}-9.0864 \times 10^{-2} \mathrm{~T}+5.4731 \times 10^{-3} \mathrm{~T}^{2}$ \\
Ice & $c_{p, \text { ice }}=2.0623 \times 10^{3}+6.0769 \mathrm{~T}$ \\
\hline
\end{tabular}

Table 1. Specific heat of different food components as a function of temperature $\left(-40^{\circ} \mathrm{C} \leq \mathrm{T} \leq 150^{\circ} \mathrm{C}\right)[12]$. 


$$
c_{p, \text { food }}=4190-2300 w_{s}-628 w_{s}^{3}
$$

where $\mathrm{w}_{\mathrm{s}}$ refers to the mass fraction of the solid components found in the food produce.

If food is frozen, Eq. (3) is used to calculate apparent specific heat [33]

$$
c_{p, a}=1550+1260 w_{s}+\frac{w_{s} R T_{0}^{2}}{M_{s} T^{2}}
$$

where $R$ is ideal gas constant, $T_{o}$ is freezing point of water $(\mathrm{K}), T$ is temperature of food $\left({ }^{\circ} \mathrm{C}\right)$ and $M_{S}$ is effective molar mass of food solids.

When effective molar mass $\left(\mathrm{M}_{\mathrm{s}}\right)$ of the soluble solid is not known, Eq. (4) is used to estimate apparent specific heat capacity

$$
c_{p, a}=1550+1260 w_{s}-\frac{\left(w_{w 0}-w_{b}\right) L_{0} T_{f}}{T^{2}}
$$

In this equation, $w_{s}, w_{w 0}$ and $w_{b}$ are mass fraction of solid, ice and free water and bound water, respectively. $L_{0}$ is the latent heat of fusion of water and $T$ is temperature of food in ${ }^{\circ} \mathrm{C}$.

\subsubsection{Enthalpy of foods}

Specific enthalpy consists of sensible energy, and it is derived by integrating expressions of specific heat capacity with respect to temperature above the freezing point [34].

$$
d h=c_{p} d T
$$

The enthalpy of food produce is the sum of mass average of the enthalpy of the food components as shown in Eq. (6).

$$
h_{\text {food }}=\sum_{i=1}^{n} h_{i} w_{i}=\sum \int c_{i} w_{i} d T
$$

Below the freezing temperature, the equation becomes [33]

$$
h=h_{f}+\left(T-T_{f}\right)\left(4190-2300 w_{s}-628 w_{s}^{3}\right)
$$

where $h_{f}$ is the specific enthalpy at the initial freezing point and $T$ and $T_{f}$ are temperature and initial freezing temperature of food, respectively.

\subsubsection{Entropy of foods}

Specific entropy is derived by integrating expressions of specific heat capacity with respect to temperature as shown below 


$$
d s=c_{p} \frac{d T}{T}
$$

The enthalpy of food produce is the sum of mass average of the entropy of the food components

$$
s_{\text {food }}=\sum_{i=1}^{n} s_{i} w_{i}
$$

where $s$ is the entropy of food and $w_{i}$ is the mass fraction of the components [8].

\subsubsection{Calculations}

Exergy of a product is composed of its physical, chemical, potential and kinetic exergy [8].

$$
E x_{t o t a l}=E x_{p h}+E x_{c h}+E x_{p o t}+E x_{k i n}
$$

However, thermal exergy which is composed of physical and chemical exergy is important from engineering thermodynamics point of view and also food engineering applications.

\subsubsection{Physical exergy}

The physical exergy is the maximum useful work obtained from a system by passing the unit of mass of a component of its state to the environmental state $\left(T_{0}, P_{0}\right)$. If potential and kinetic exergy is ignored, the physical exergy value is calculated by using enthalpy and entropy value of the component as follows:

$$
e x_{p h}=\left[\left(h(T, P)-h_{0}\left(T_{0}, P_{0}\right)\right]-T_{0}\left[\left(s(T, P)-s_{0}\left(T_{0}, P_{0}\right)\right]\right.\right.
$$

where the subscript zero refers to reference environment at $P_{0}$ and $T_{0}$ (in K).

If the enthalpy and entropy values of the food components are unknown, the enthalpy and entropy differences can be calculated and placed to the equation above (Eq. (11)) [8].

In the food engineering operations, water and air are mostly used components for drying, cooling, washing, and so on. For that reason, it is necessary to mention about their exergy calculations besides food commodities. In the case of enthalpy calculation of pure or homogeneous mixture (e.g., water), enthalpy equation is as follows:

$$
d h=c_{p} d T+v d P
$$

and the entropy term is shown in Eq. (13)

$$
d s=c_{p} \frac{d T}{T}
$$

After necessary derivation, the physical exergy of substances can be computed rough as follows: 


$$
e x_{p h}=c_{p}\left(T-T_{0}\right)-T_{0} c_{p} \ln \frac{T}{T_{0}}+v\left(P-P_{0}\right)
$$

This equation might be applied for incompressible condensed substance for small temperature and pressure differences.

In the case of ideal gas substance (pure or constant composition, e.g., air), the temperaturedependent enthalpy difference is calculated by the formula

$$
h-h_{0}=\int_{T_{0}}^{T} c_{p} d T
$$

For the entropy, the difference is explained as below

$$
s-s_{0}=\int_{T_{0}}^{T} c_{p} \frac{d T}{T}-R \int_{P_{0}}^{P} \frac{d P}{P}=\int_{T_{0}}^{T} c_{p} \frac{d T}{T}-R \ln \frac{P}{P_{0}}
$$

If $c_{p}$ is assumed constant, the physical exergy equation is as follows

$$
e x_{p h}=c_{p}\left(T-T_{0}\right)-T_{0} c_{p} \ln \frac{T}{T_{0}}+R T_{0} \ln \frac{P}{P_{0}}
$$

The exergy of air is calculated from

$$
\begin{aligned}
e x_{\text {air }}= & \left(c_{p, \text { air }}+\omega * c_{p, v}\right)\left(T-T_{0}\right)-T_{0}\left\{\left(c_{p, \text { air }}+\omega * c_{p, v}\right) \ln \frac{T}{T_{0}}-\left(R_{\text {air }}+\omega R_{v}\right) \ln \frac{P}{P_{0}}\right\} \\
& +T_{0}\left\{\left(R_{\text {air }}+\omega R_{v}\right) \ln \left(\frac{1+1,6078 \omega_{0}}{1+1,6078 \omega}\right)+1,6078 \omega R_{\text {air }} \ln \left(\frac{\omega}{\omega_{0}}\right)\right\}
\end{aligned}
$$

where $\omega$ is the specific humidity ratio is.

The exergy of water

$$
e x_{\text {water }}=\left(h_{f}-h_{g, 0}\right)+v_{f}\left(P-P_{g}\right)-T_{0}\left(s_{f}-s_{g, 0}\right)+T_{0} R_{v} \ln \left(\frac{P_{g, 0}}{x_{v, 0} P_{0}}\right)
$$

\subsubsection{Chemical exergy}

The standard chemical exergy values of most of the elements are given by Szargut et al. [8]. Chemical exergy of a species at reference state is the sum of the standard Gibbs free energy of formation and standard chemical exergies of its elements

$$
e x_{c h, j}^{0}=\Delta G_{f o r, j}^{0}+\sum v_{k} E x_{c h, k}^{0}
$$

where $v_{k}$ is the stoichiometric constant of kth element in the species. Calculation of chemical exergy of species at a definite state is 


$$
e x_{c h, j}=\Delta G_{f, j}^{T}+\sum v_{k} E x_{c h, k}^{0}
$$

Following equation describes how the chemical exergy of a stream is calculated:

$$
e x_{c h}=\sum x_{i} E x_{c h, i}
$$

where $x_{i}$ is the mass fraction of ith element in the species.

For industrial fuels, an approximate calculation of chemical exergy might be computed by using lower heating value (LHV) and higher heating value (HHV).

$$
e x_{c h}=f_{l} L H V=f_{h} H H V
$$

where $f_{1}$ and $f_{h}$ are empricial coefficients for LHV and HHV, respectively.

\subsubsection{Exergy of non-matter streams}

\subsection{Exergy of work}

Exergy of work equals to its value.

$$
E \dot{x}_{\text {work }}=\dot{W}
$$

\subsection{Exergy of electricity}

The energy content of electricity is directly converted to work and the exergy of electricity

$$
E \dot{x}_{e}=\dot{W}_{e}
$$

\subsection{Exergy of heat flows}

The exergy content of a heat flow $\dot{Q}$ at a temperature is of

$$
E \dot{x}_{\text {heat }}=\left(1-\frac{T_{0}}{T}\right) \dot{Q}
$$

$\dot{Q}$ and $\mathrm{T}$ are the heat transfer rate from the system to the surrounding and temperature of surrounding.

\subsection{Exergy analysis methodology}

A general balance equation for a control volume is written as follows

$$
\text { Input }- \text { Output }+ \text { Generation }- \text { Consumption = Accumulation }
$$

This general balance equation is applied for mass, energy, entropy and exergy. In the general equation, input and output refer to energy or matter transfer from the surrounding to the control 
volume and from control volume to surrounding, respectively. Generation and consumption indicate the quantity generated and consumed in the control volume, respectively. Accumulation term defines accumulated quantity in the control volume.

\subsubsection{Mass balance}

In the general steady-state mass balance equation (Eq. (26)), the mass enters to the system equals to the mass exits from the system and the rate form is as follows:

$$
\sum \dot{m}_{\text {in }}=\sum \dot{m}_{\text {out }}
$$

\subsubsection{Energy balance}

The first law of thermodynamics deals with conservation of energy, which means that the input of energy equals the output of energy and energy conservation law is shown below for steady-state sytems

$$
\sum \dot{E}_{\text {in }}=\sum \dot{E}_{\text {out }}
$$

The second law of thermodynamics can be defined by Clausius equation as follows:

$$
\sum(\dot{m} s)_{o u t}-\sum(\dot{m} s)_{\text {in }}=\sum_{j}\left(\frac{\dot{Q}}{T}\right)_{j}+\dot{s}_{\text {gen }}
$$

where $s$ is entropy, $\dot{Q}$ is heat transfer rate through the system boundary and $\dot{s}_{\text {gen }}$ is entropy production rate due to irreversibility. The entropy term is a physical property of substances, and it is related to availability or useful work. Reversible processes are also called as ideal processes and entropy production of these processes is assumed to be zero [6]. In reality, it can never happen, and entropy always increases and all studies about energy efficiency have focused on keeping the entropy in its minimum level.

If we combine the first (Eq. (27)) and second law of thermodynamics (Eq. (28)), the equation becomes

$$
\dot{W}=\sum_{n} \dot{Q}_{n}\left(1-\frac{T_{0}}{T_{n}}\right)+\sum \dot{m}_{i n}\left(h-T_{0} s+\frac{w^{2}}{2}+g z\right)-\sum \dot{m}_{\text {out }}\left(h-T_{0} s+\frac{w^{2}}{2}+g z\right)-T_{0} \dot{s}_{g e n}
$$

which is known as the Gouy-Stodola equation [8], and it is the base of the exergy balance equation.

\subsubsection{Exergy balance}

For a steady-state system, the exergy rate equation is shown below: 


$$
\sum \dot{E x_{\text {out }}}-\sum \dot{E x_{\text {in }}}=\sum \dot{E x_{D}}=T_{0} \dot{s}_{\text {gen }}
$$

If we write the equation in terms of mass, heat and work form it becomes

$$
E \dot{x}_{\text {mass, in }}-E \dot{x}_{\text {mass, out }}+E \dot{x}_{\text {heat }}-E \dot{x}_{\text {work }}=E \dot{x}_{D}
$$

The exergy of the mass is defined as

$$
\begin{aligned}
E \dot{x}_{\text {mass, in }} & =\dot{m}_{\text {in }} e x_{\text {in }} \\
E \dot{x}_{\text {mass, out }} & =\dot{m}_{\text {out }} e x_{\text {out }}
\end{aligned}
$$

where ex is the specific exergy, $\dot{m}$ is the mass flow rate.

\subsubsection{Energy and exergy efficiency}

In the conservation of energy, only quantity of energy (kinetic, potential, thermal, mechanical, internal) is taken into account, and the energy efficiency of a system is defined as the ratio of energy released by the system to energy provided to the system.

$$
\eta=\frac{\text { Energy released by the system }}{\text { Energy provided to the system }}
$$

where $\eta$ refers to energy efficiency. However, the first law does not say anything about how to decrease energy consumption in the system of interest. It should be noted that different types of energies have different work ability or quality [6].

The exergetic performance of the processes is evaluated by means of different criteria. One of them is called universal efficiency which is defined as the ratio of exergy output to exergy input.

$$
\varepsilon_{u}=\frac{\text { Exergy output }}{\text { Exergy input }}
$$

The other one is called as functional exergy efficiency and is defined as the ratio of the exergy of the desired output to the exergy of fuel or raw material to produce desired product.

$$
\varepsilon_{f}=\frac{\text { Exergy of the desired output }}{\text { Exergy of raw material }}
$$

\subsubsection{Exergetic performance indicators}

For a process or system, if the exergy loss or irreversibility is minimized, the maximum improvement obtained. Van Gool [35] developed an equation for improvement potential and this relation is as follows

$$
I \dot{P}=(1-\varepsilon)\left(E \dot{x}_{\text {in }}-E \dot{x}_{\text {out }}\right)
$$

where $I \dot{P}$ is the improvement potential in the rate form. 
It should be noticed that if we deal with complex food processes, it is necessary to divide the processes into several units and assess exergy destruction for each unit to determine which unit operation is more inefficient in terms of thermodynamics. In addition to improvement potential, some other performance indicators such as relative irreversibility, exergetic factor, sustainability index used in exergy analysis defined as follows [36]:

$$
\begin{gathered}
\text { Improvement potential rate: } \dot{I P}=(1-\varepsilon)\left(\dot{E x_{f}}-\dot{E x_{p}}\right) \\
\text { Relative irreversibility: } R I_{k}=\left(\dot{E x_{D, k}} / \dot{E x_{D, t o t}}\right) \times 100 \\
\text { Exergetic factor: } f_{k}=\left(\dot{E x_{f, k}} / \dot{E x_{f, t o t}}\right) \times 100 \\
\text { Sustainability index: } S I=1 /(1-\varepsilon)
\end{gathered}
$$

\section{Applications of exergy analysis on dairy processes}

Up to know, exergy analysis has been applied most of the engineering processes. In last decades, exergetic assessments of dairy processes have an increase attention. In this section, some of the examples of exergetic assessment of dairy processes are tabulated (Table 2) and briefly summarized.

Soufiyan et al. [31] studied exergetic performance assessment of a long-life milk processing plant. The investigated plant, shown in Figure 2, consisted of four main lines as steam generator, above-zero refrigeration system, milk reception, pasteurization, and standardization line, and ultra-high-temperature (UHT) milk processing unit while the main components of the steam generator line are the condensate tank, shell and tube heat exchanger, fire tube boiler with a fuel injection system and an air compressor, pressure reducing valves, pumps and steam trapping devices; the gasket plate heat exchanger, storage tanks with agitators, balance tank, deaerator with a vacuum pump, flow controller, centrifugal fat extraction apparatus, mixing devices, homogenizer, bactofuge, holding tube are the main components of the milk reception, pasteurization, and standardization line.

\begin{tabular}{llr}
\hline Study & Authors & Year \\
\hline Long-life milk processing & Soufiyan MM, Aghbashlo M, Mobli H & 2017 \\
Industrial-scale yoghurt production & Jokandan MJ, Aghbashlo M, Mohtasebi SS & 2015 \\
Yoghurt drink production & Soufiyan MM and Aghbashlo M & 2017 \\
Cheese powder production & Erbay Z, Koca N, Kaymak-Ertekin F, Ucuncu M & 2015 \\
Flavored yoghurt production process & Sorgüven E and Özilgen M & 2012 \\
Milk pasteurization process & Yildirim N and Genc S & 2015 \\
Milk powder production & Yildirim N and Genc S & 2017 \\
\hline
\end{tabular}

Table 2. The studies on exergetic assessment of dairy processes in open literature. 


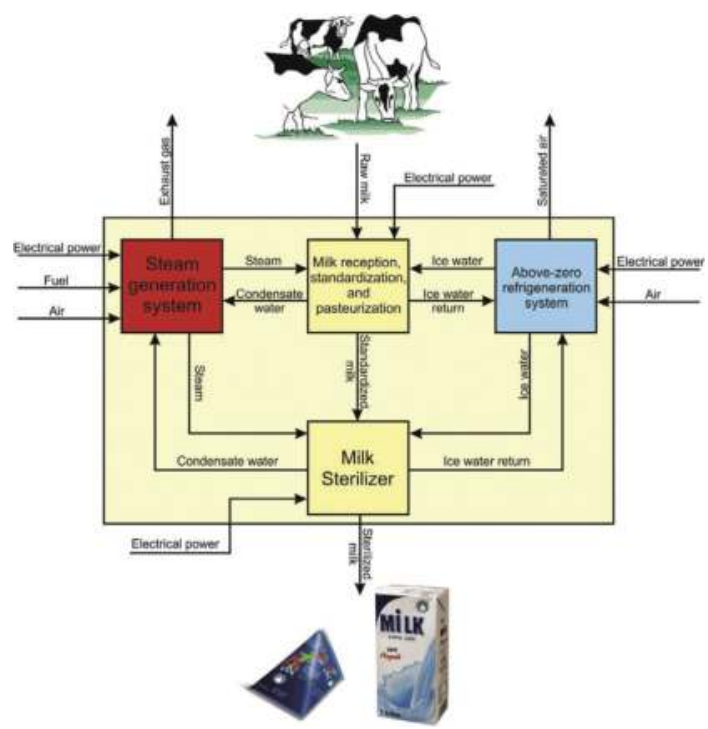

Figure 2. General description of the long-life milk processing plant of the investigated factory [31].

In the system of interest, the specific exergy destruction for production of the $1 \mathrm{~kg}$-long-life milk was found to be $345.50 \mathrm{~kJ} / \mathrm{kg}$. While the highest contribution to the specific exergy destruction of the long-life milk processing $(60.70 \%)$ belonged to the steam generation system, the specific exergy destruction of the milk reception, pasteurization, and standardization line, and UHT milk-processing unit were determined as 1.63 and $49.54 \mathrm{~kJ} / \mathrm{kg}$, respectively.

A detailed exergetic analysis of an industrial yoghurt production plant is conducted by Jokandan et al. (Figure 3) [27]. The percentile contributions for yoghurt production lines was obtained as $5.21 \%$ of the total specific exergy consumption of the pasteurized yoghurt production plant with the value of $841.34 \mathrm{~kJ} / \mathrm{kg}$ to produce $3.75 \%$ fat yoghurt with $1.46 \mathrm{~kg} / \mathrm{s}$ mass flow rate.

In a similar study of Soufiyan and Aghbashlo, 2017 [31] yoghurt drink manufacturing was investigated by using the same milk processing line as explained above (Figure 2). The specific exergy destruction of yoghurt drink manufacturing line was determined as $118 \mathrm{~kJ} / \mathrm{kg}$ which is $26.7 \%$ of whole system's specific exergy destruction of $442 \mathrm{~kJ} / \mathrm{kg}$ (Figure 4).

Erbay et al. [28] studied optimization of pilot-scale cheese powder production by using a pilotscale spray drier and nonenzymatic browning index, free fat content, solubility index, bulk density and exergy efficiency values were determined at the optimum condition. Optimum operating conditions were provided at $174^{\circ} \mathrm{C}$ inlet and $68^{\circ} \mathrm{C}$ outlet drying temperature with $354 \mathrm{kPa}$ atomization pressure of $354 \mathrm{kPa}$. The exergetic efficiency was obtained as $4.81 \%$ at the optimum operating condition as seen in Figure 5.

Sorguven and Ozilgen [30] investigated energy utilization, carbon dioxide emission, and exergy loss in flavored yoghurt production process (Figure 6). The results show that $53 \%$ of the total exergy loss occurred during the milk production and $80 \%$ of the total work input 


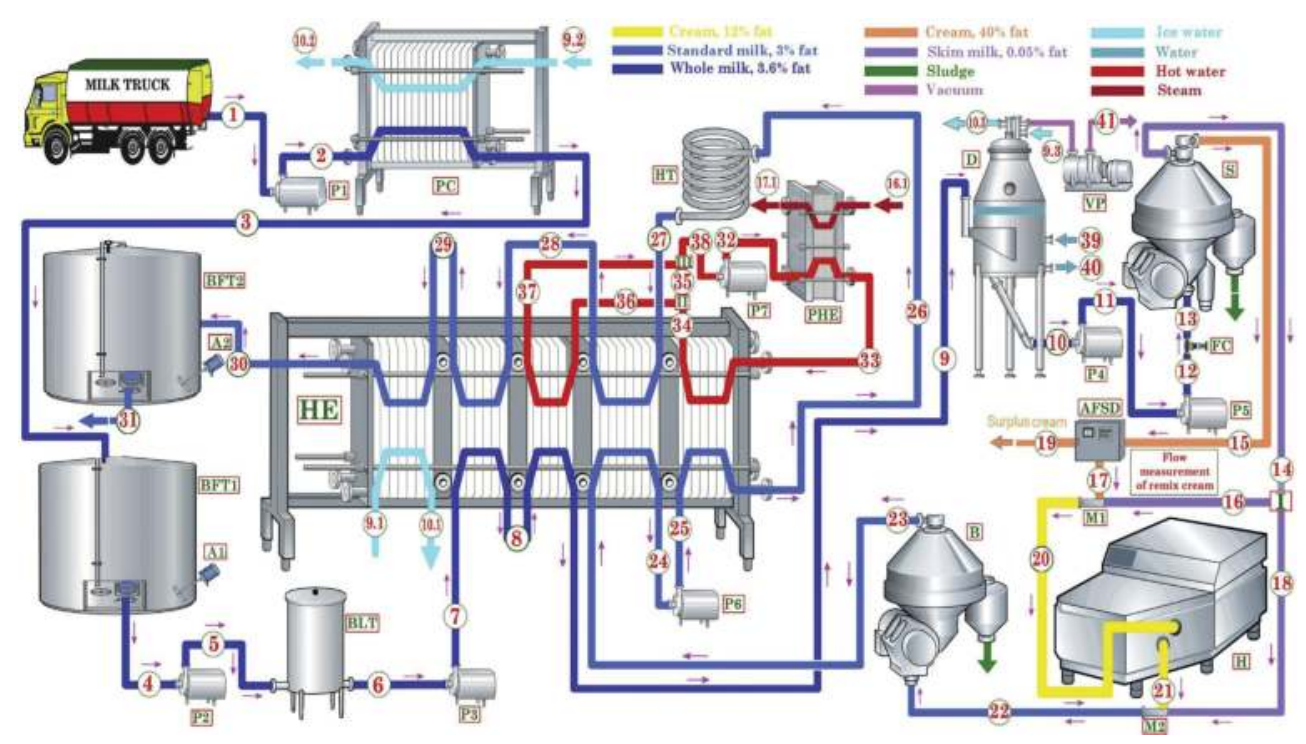

Figure 3. Schematic illustration of the yoghurt production line of the investigated dairy company [27].

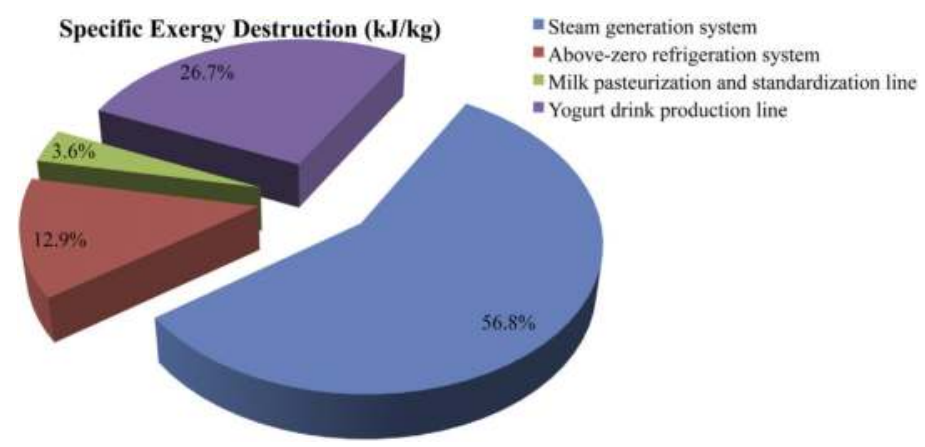

Figure 4. Specific exergy destruction fraction of yoghurt drink manufacturing factory [31].

was consumed during the plain yoghurt making process. The cumulative degree of perfection was $3.6 \%$ for the strawberry-flavored yoghurt. This value can rise up to $4.6 \%$, if renewable energy resources like hydropower and algal biodiesel are employed instead of fossil fuels.

Thermodynamic analysis of a milk pasteurization process assisted by geothermal energy (illustrated in Figure 7(a)) was studied by Yildirim and Genc, 2015 [24]. In the system, a waterammonia VAC (vapor absorption cycle), a cooling section, a pasteurizer and a regenerator were used for milk pasteurization. The universal and functional exergetic efficiencies were considered in the study. While the exergetic efficiency of the whole system was calculated as $56.81 \%$ with total exergy destruction rate of $13.66 \mathrm{~kW}$, the functional exergetic efficiency of pasteurization was 


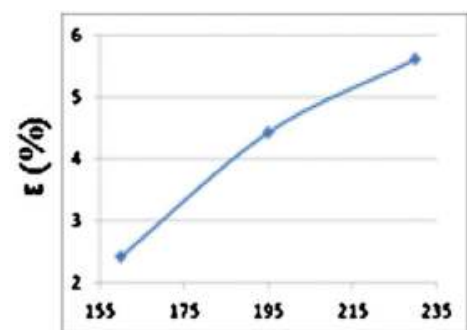

$T_{\text {in }}\left({ }^{\circ} \mathrm{C}\right)$

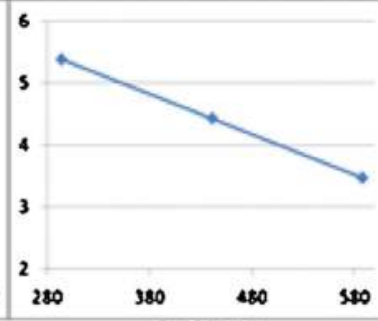

$\mathbf{P}(\mathrm{kPa})$

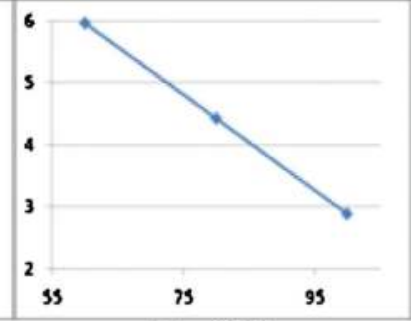

$\mathrm{T}_{\text {out }}\left({ }^{\circ} \mathrm{C}\right)$

Figure 5. Exergy efficiencies at the optimum conditions [28].

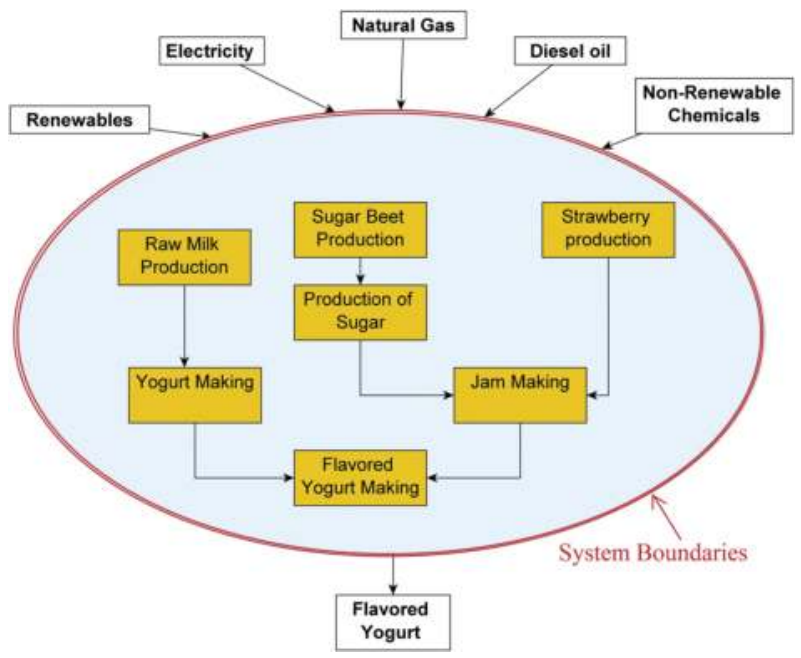

Figure 6. Schematized diagram of overall system [30].

determined as $25.8 \%$. The effect of geothermal resource temperature and geothermal resource flow rate on the exergetic efficiency of the whole system for $1 \mathrm{~kg} / \mathrm{s}$ mass flow rate of milk was investigated. The results showed that the maximum efficiency can be obtained by using lower temperature and higher flow rate of the geothermal resource (Figure 7(b)).

Yildirim and Genc [25] studied a thermodynamic analysis including comprehensive exergy analysis by using different performance parameters such as exergy efficiency, improvement potential rate, sustainability index, relative irreversibility and exergetic factor for the milk powder production system. The schematic diagram of the milk powder production line is illustrated in Figure 8. The considered system consists of an evaporator, a feed pump, a spray drier, a cooler, an economizer, a fan, a heater, and a compressor. Thermal energy needed for the production line was provided by geothermal energy. 


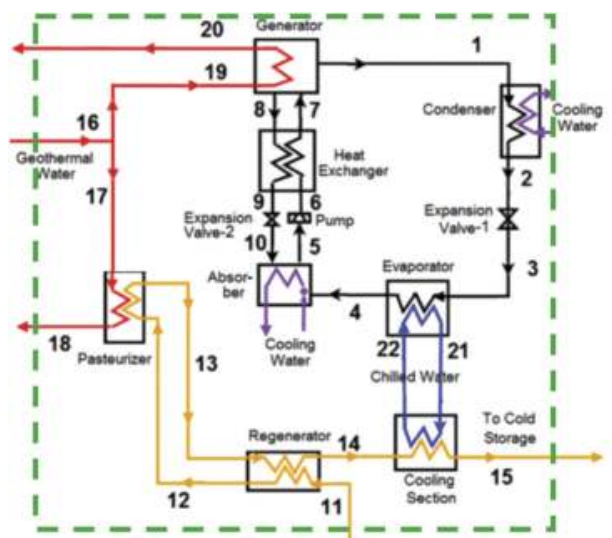

(a)

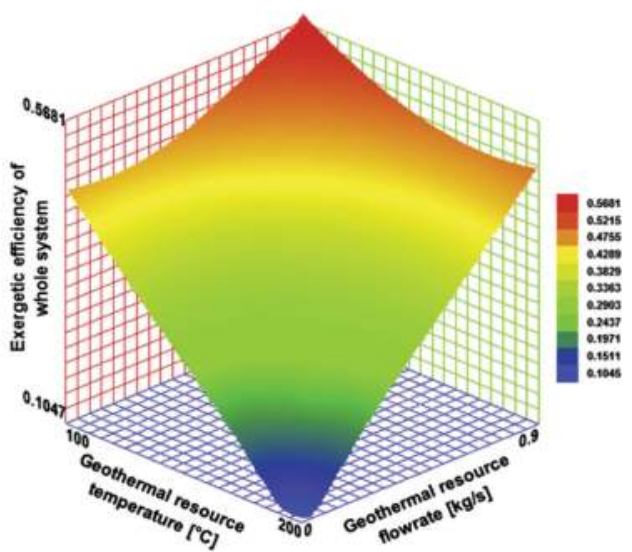

(b)

Figure 7. (a) Schematic of the system of a milk pasteurization process assisted by geothermal energy and (b) the effect of geothermal resource temperature and geothermal resource flow rate on the exergetic efficiency of the whole system [24].

The overall energy and exergy efficiencies of the whole milk powder production system were calculated as 85.4 and $57.45 \%$, respectively. In the considered system, the evaporator has the highest $(333.60 \mathrm{~kW})$ exergy destruction rate and relative irreversibility $(75.8 \%)$. Therefore, the evaporator has the highest improvement potential rate $\dot{P}(191.1 \mathrm{~kW})$. Grassman diagram is mostly used to represent exergy streams graphically. In the diagram, the width of each arrow is scaled according to their magnitude and in this way, all exergy destructions take place in the system can be seen clearly with their values. As an example, in the study of Yildirim and Genc

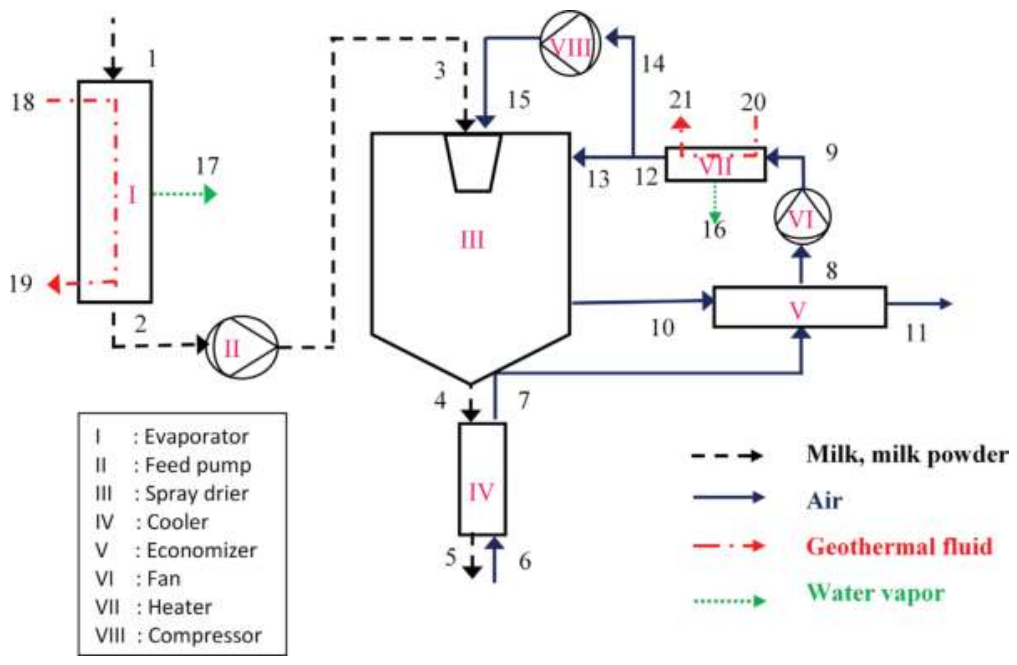

Figure 8. Schematic diagram of the milk powder production line [25]. 


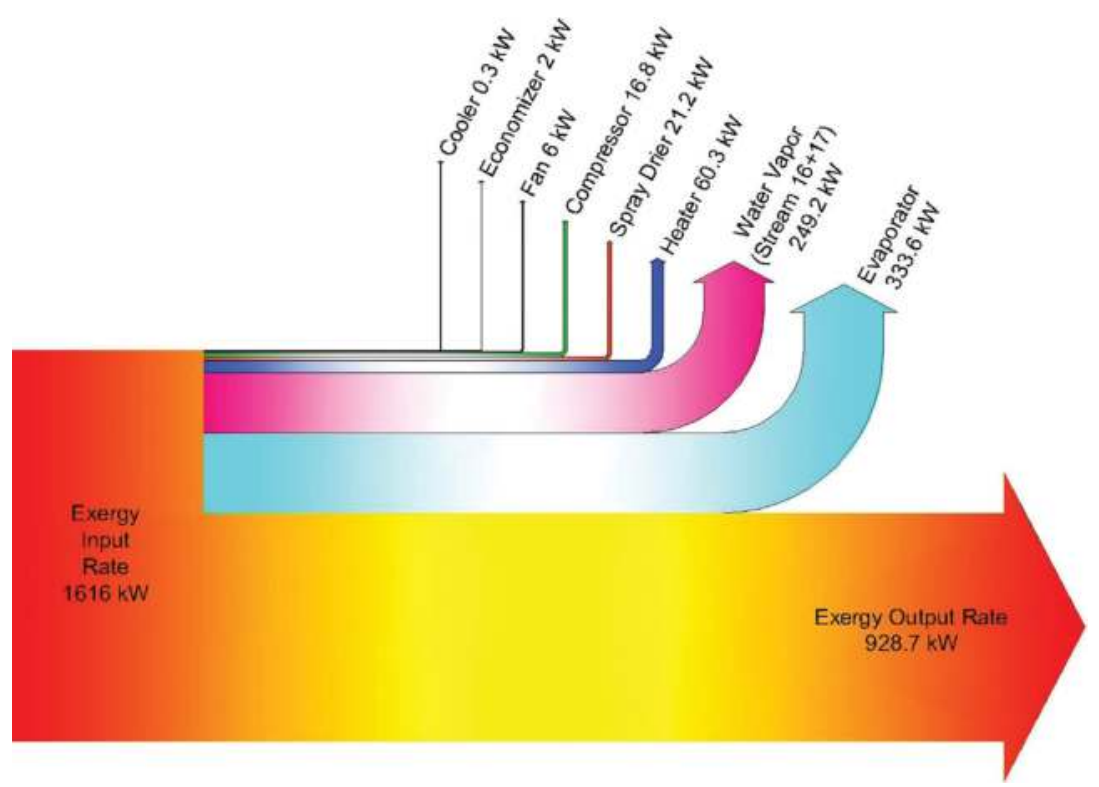

Figure 9. Grassmann diagram of the milk powder production process assisted by geothermal energy [25].

[25], exergy fluxes and destructions in the milk powder system are shown in the Grassman diagram in Figure 9.

\section{Conclusion}

The first law analysis is widely used for the assessment of many systems from living organisms to machine system. Recently, a number of exergy analysis applications have been increasing since it is a more useful tool to assess the performance of systems and support sustainable development. In this chapter, exergy analysis methodology of food processes was presented, and some important exergy analysis applications (e.g., yoghurt production, milk pasteurization process, milk powder production) of dairy industry were reviewed. Although, the exergy analysis provides to design more efficient and sustainable approaches to food industry, it has still been is at very beginning stage. Besides, thermodynamic optimization can be conducted on dairy processes to determine the best performance in terms of exergetic perspective. As a result of energy and exergy analysis, utilization of renewable energy sources becomes prominent due to high energy need of dairy industry. Furthermore, exergoeconomic analysis that integrates economics with exergy can be a useful tool to assess the effect of both economics and thermodynamics. Additionally, environmental impact of dairy industry can be determined by life cycle assessment and exergetic life cyle assessment which takes into consideration both exergy and life cycle assessment. 


\section{Acknowledgements}

The author would like to thank the reviewers for their valuable and constructive comments, which have been very useful in improving the quality of the chapter.

\section{Conflict of interest}

There are no conflicts of interest to declare. SG is the author of the manuscript and no one else contributed to the design and writing of the manuscript.

\section{Nomenclature}

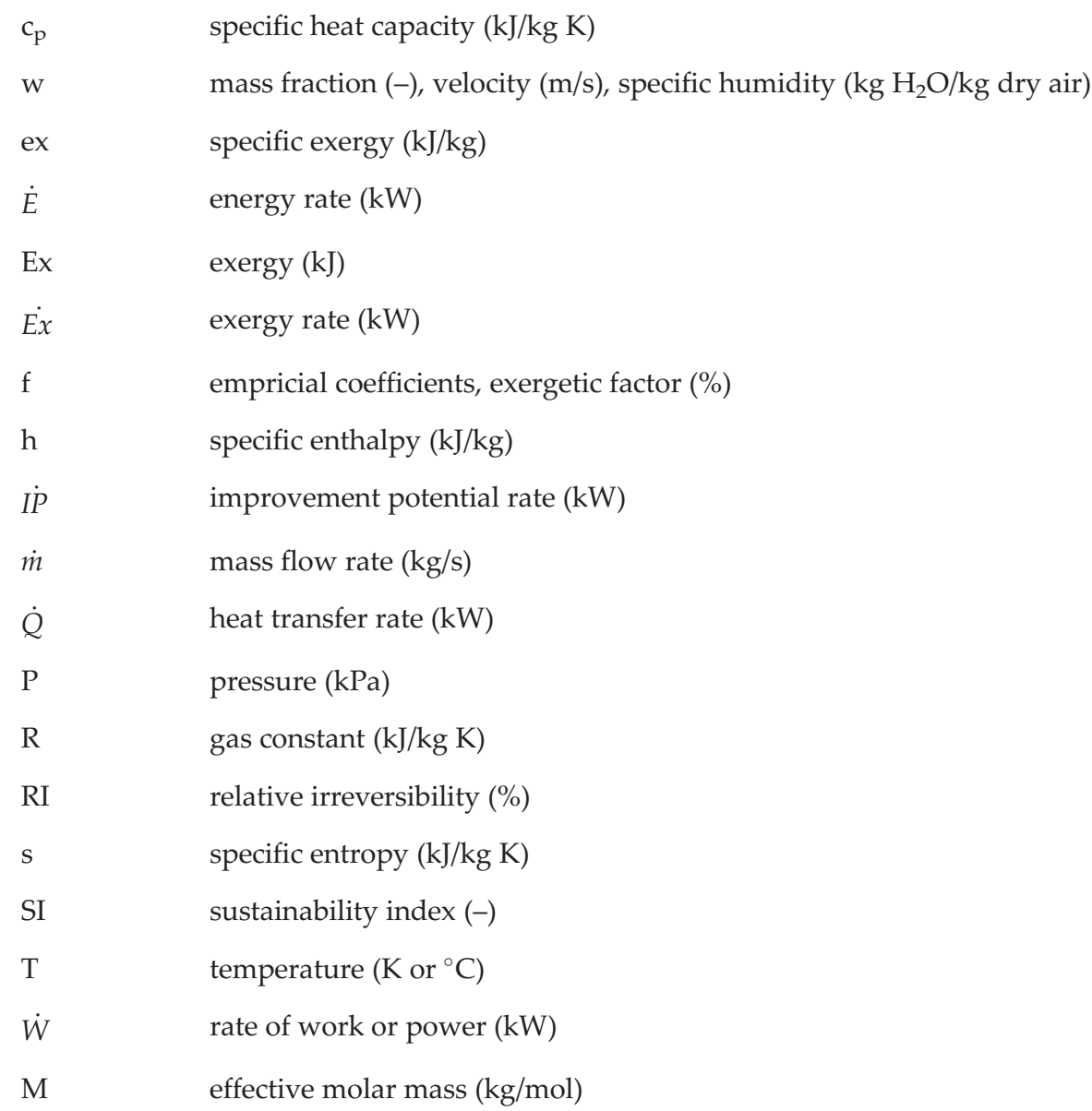


$\mathrm{L} \quad$ latent heat $(\mathrm{kJ} / \mathrm{kg})$

x mole fraction (-)

Greek letters

$\begin{array}{ll}\eta & \text { thermal (the first law) efficiency }(-) \\ \varepsilon & \text { exergetic (the second law) efficiency }(-) \\ v & \text { specific volume }\left(\mathrm{m}^{3} / \mathrm{kg}\right)\end{array}$

Subscript

a

air

ch

D

e

$\mathrm{f}$

for

g

gen

heat

in

$\mathrm{k}$

kin

out

$\mathrm{p}$

past

ph

pot

$\mathrm{s}$

tot

$\mathrm{u}$

$v$ apparent

air

chemical

destruction, destroyed

electricity

freezing, functional, fuel

formation

gas

generation

heat

input, inlet

location

kinetic

output

product

pasteurizer

physical

potential

solid

total

universal

vapor 
$\begin{array}{ll}\text { water } & \text { water } \\ \text { work } & \text { work } \\ 0 & \text { dead/reference/environmental state }\end{array}$

\section{Author details}

Seda Genc

Address all correspondence to: seda.genc@yasar.edu.tr

Food Processing Department, Vocational School, Yasar University, Bornova, İzmir, Turkey

\section{References}

[1] Walstra P, Wouters JTM, Geurts TJ. Dairy Science and Technology. 2nd ed. Boca Raton: Taylor \& Francis; 2006

[2] Bylund G. Dairy Processing Handbook, Tetra Pak Processing Systems AB S-221 86 Lund, Sweden; 1995

[3] Food and Agriculture Organizations of the United Nations Statistics Division. Available from: http://faostat3.fao.org/browse/Q/QL/E [Accessed: 2017-November-23]

[4] The statistical portal. Available from https://www.statista.com/statistics/502280/globaldairy-market-value/ [Accessed: 2017-November-31]

[5] Food and Agriculture Organizations of the United Nations Statistics Division. Available from: http://www.fao.org/wairdocs/lead/x6114e/x6114e06.htm [Accessed: 2017-September-12]

[6] Cengel YA, Boles MA. Thermodynamics - An Engineering Approach. Tata McGraw Hill: New Delhi; 2002

[7] Bejan A. Advanced Engineering Thermodynamics. 3rd ed. New York: Wiley; 2006

[8] Szargut J, Morris DR, Steward FR. Exergy Analysis of Thermal, Chemical and Metallurgical Processes. New York: Hemisphere; 1988

[9] Bejan A. Shape and Structure, from Engineering to Nature. Cambridge, UK: Cambridge University Press; 2000

[10] Bejan A, Tsatsaronis G, Moran M. Thermal Design and Optimization. New York: Wiley; 1996

[11] Dincer I, Rosen M. Exergy-Energy, Environment and Sustainable Development. 1st ed. Oxford: Elsevier; 2007 
[12] Choi Y, Okos MR. Effects of temperature and composition on the thermal properties of foods. In: Food Engineering and Process Applications 1. London: Elsevier Applied Science Publishers; 1986. pp. 93-101

[13] Esen H, Inalli M, Esen M, Pihtili K. Energy and exergy analysis of a ground-coupled heat pump system with two horizontal ground heat exchangers. Building and Environment. 2007;42:3606-3615

[14] Esen H, Inalli M, Esen M. Technoeconomic appraisal of a ground source heat pump system for a heating season in eastern Turkey. Energy Conversion and Management. 2006;47:1281-1297

[15] Taner T, Sivrioglu M. A techno-economic \& cost analysis of a turbine power plant: A case study for sugar plant. Renewable and Sustainable Energy Reviews. 2017;78:722-730

[16] Taner T, Sivrioglu M. Energy \& exergy analysis and optimisation of a model sugar factory in Turkey. Energy. 2015;93:641-654

[17] Taner T. Energy and exergy analyze of PEM fuel cell: A case study of modeling and simulations. Energy. 2018;143:284-294

[18] Taner T. Optimisation processes of energy efficiency for a drying plant: A case of study for Turkey. Applied Thermal Engineering. 2015;80:247-260

[19] Genc S, Sorguven E, Kurnaz IA, Ozilgen M. Exergetic efficiency of ATP production in neuronal glucose metabolism. International Journal of Exergy. 2013;13:60-84

[20] Genc S, Sorguven E, Ozilgen M, Kurnaz IA. Unsteady exergy destruction of the neuron under dynamic stress conditions. Energy. 2013;59:422-431

[21] Genc S, Hepbasli A. Performance assessment of a potato crisp frying process. Drying Technology. 2015;33:865-875

[22] Genc S. Energy analysis in industrial grape molasses (pekmez) production process. Akademik Gida. 2017;15(1):51-59

[23] Genc M, Genc S, Goksungur Y. Exergy analysis of wine production: Red wine production process as a case study. Applied Thermal Engineering. 2017;117:511-521

[24] Yildirim N, Genc S. Thermodynamic analysis of a milk pasteurization process assisted by geothermal energy. Energy. 2015;90:987-996

[25] Yildirim N, Genc S. Energy and exergy analysis of a milk powder production system. Energy Conversion and Management. 2017;149:698-705

[26] Genc S, Yildirim N. Sustainable dairy industry by using renewable energy source. Celal Bayar University Journal of Science. 2017;13(3):665-670

[27] Jokandan MJ, Aghbashlo M, Mohtasebi SS. Comprehensive exergy analysis of an industrial-scale yogurt production plant. Energy. 2015;93:1832-1851 
[28] Erbay Z, Koca N, Ertekin-Kaymak F, Ucuncu M. Optimization of spray drying process in cheese powder production. Food and Bioproducts Processing. 2014;93:156-165

[29] Munir MT, Yu W, Young BR. Can exergy be a useful tool for the dairy industry? Proceedings of the 24th European symposium on computer aided process engineeringESCAPE. 2014;24(33):1129-1134

[30] Sorgüven E, Ozilgen M. Energy utilization, carbon dioxide emission, and exergy loss in flavoured yogurt production process. Energy. 2012;40:214-225

[31] Soufiyan MM, Aghbashlo M, Mobli H. Exergetic performance assessment of a long-life milk processing plant: A comprehensive survey. Journal of Cleaner Production. 2017;140: 590-607

[32] Soufiyan MM, Aghbashlo M. Application of exergy analysis to the dairy industry: A case study of yogurt drink production plant. Food and Bioproducts Processing. 2017;101:118-131

[33] Chen CS. Thermodynamic analysis of the freezing and thawing of foods: Enthalpy and apparent specific heat. Journal of Food Science. 1985;50(4):1158-1162

[34] Fricke B, Becker B. Evaluation of thermophysical property models for foods. HVAC\&R Research. 2001;7(4):311-330

[35] Van Gool W. Energy policy: Fairly tales and factualities. In: Soares ODD, Martins da Cruz A, Costa Pereira G, Soares IMRT, Reis AJPS, editors. Innovation and TechnologyStrategies and Policies. Dordrecht: Kluwer; 1997. pp. 93-105

[36] Hepbasli A. A review on energetic, exergetic and exergoeconomic aspects of geothermal district heating systems (GDHSs). Energy Conversion and Management. 2010;51(10): 2041-2061 
